\title{
SEN RIKYŨ
}

Kensuke Tamai

Palestra proferida em 26 de junho, no Centro de Estudos Japoneses da USP.

Hoje, vou falar sobre SEN RIKYŪ. Falar quem foi Sen Rikyū no "Chado" (Caminho do Chá) num tempo curto, é uma coisa tão difícil como falar quem foi Shakespeare na Literatura Inglesa, Goethe na Literatura Alemã ou Camões na Literatura Portuguesa. Além disso, neste auditório, devem estar presentes especialistas de "Chadö" e pessoas que já tenham um profundo conhecimento sobre Rikyū. Hoje, porém, gostaria de me dirigir mais às pessoas que vão se iniciar no "Chad $\bar{o}^{\prime \prime}$, ou que pretendem especializar-se no assunto, proferindo uma palestra bem elucidativa, como uma introdução a Sen Rikyū.

Sen Rikyū foi um "chajin" que morreu aos 70 anos, fazendo "harakiri"(1), no dia 28 de fevereiro de 1951, há 391 anos. "Chajin" era uma pessoa para quem o "Chado" era um entretenimento pessoal. Ao mesmo tempo, era professor de chá. Como vou pormenorizar mais tarde, "chajin" era a figura que servia aos grandes senhores, preparando "chakai" (reuniões para apreciar o Chá), patrocinados por eles, recebendo e servindo os convidados, pessoalmente.

Dizem que os antepassados de Rikyū eram originários de Chiba, província vizinha da atual Tóquio, e que seu antigo sobrenome era $\mathrm{Mi}$ namoto. Mas no Japão antigo, costumava-se forjar a árvore genealógica para mostrar que seus antepassados eram de família nobre, adotando um dos quatro sobrenomes das famílias nobres da época: Minamoto, Taira, Fujiwara e Tachibana. Assim, a tese que atribui a Rikyū a descendência de Minamoto não é muito digna de crédito. Há outros pesquisadores que propõem ser Rikyū descendente de 
coreanos. Esta tese, porém, ainda não está suficientemente provada pelos documentos existentes. Mas está provado que o primeiro antepassado de Rikyú imigrou para Quioto na centúria de 1200, adotou o sobrenome Tanaka e, mais tarde, durante a Guerra Civil de Onin, que começou no ano de 1467, abandonou Quioto e estabeleceu-se em Sakai, cidade portuária da província de Ōsaka.

Yohee Tanaka, pai de Rikyū, teve grande êxito comercial em Sakai, cómo atacadista de peixe e proprietário de armazéns. Tornou-se rico e famoso na cidade e passou a usar o sobrenome Sen, tomando a primeira parte do nome do pai Sen'Ami. Portanto, atualmente o sobrenome Sen tem, geralmente, alguma relação com Rikyū. Neste momento se encontra em São Paulo, o cantor Japonês Sen Masao. O seu sobrenome, se for artístico, não apresenta problema, mas se for sobrenome verdadeiro, causa uma certa estranheza, pois ele é da província de I wate.

Rikyū nasceu em Sakai, como primogênito de Yohee. Seu pai faleceu quando ele contava 19 anos, deixando-lhe uma grande fortuna. Seu verdadeiro nome é Yoshirō, sendo Rikyū, o título que recebeu com a idade de 64 anos.

Atualmente, Sakai não possui muitas características especiais, apesar de ser uma cidade com 800.000 habitantes, na província de Ōsaka. Mas Sakai, na época de Rikyū, era muito próspera como porto de comércio exterior com a China, Coréia e Ryūkyū latual Okinawa). Por iniciativa dos proprietários dos armazéns do porto, os comerciantes da cidade formaram uma organização autônoma, defendiam a própria cidade e se opunham ao regime dos samurais. Nem os mais poderosos da época conseguiam dominá-los. Portanto, os comerciantes de Sakai tinham muito orgulho, e esse fato vai provocar a trágica morte de Rikyū, sobre o que vou thes falar mais tarde.

Um jesuíta português chamado Luís Frois, que estava no Japão nessa época, escreveu sobre a cidade de Sakai: "os cidadãos de Sakai são muito arrogantes e orgulhosos. São ambiciosos, obtêm lucros excessivos e estão sempre perdidos em prazeres. Quando Ihes foi dito que teriam de abandonar toda a fortuna e o orgulho para entrar no $\mathrm{Pa}$ raíso eles responderam que nesse caso, preferiam não entra no Paraíso".

Um outro português, Gaspar Coelho, descreve a cidade desta forma: "Sakai é uma grande cidade onde há vários comerciantes ricos. E uma cidade liberal, republicana e é tão linda e opulenta que nenhuma outra cidade japonesa pode ser comparada a ela. Sakai possui privilégios e liberdades. Mesmo quando as outras cidades estão envol- 
vidas em guerras trágicas, ela está gozando de paz". Por estas descrições, podemos entender as características de Sakai nessa época.

Quanto à idade em que Rikyū começou a aprender a arte do Chá, supõe-se que tenha sido por volta dos 10 anos, devido a um documento antigo que registra um "chakai" patrocinado por ele, no ano de 1536, em Quioto, quando contava 16 anos.

Os motivos por que Rikyū veio a se interessar pelo Chá, podem ter sido dois: primeiro, o de ser o "Chado", nessa época, um aprendizado indispensável para a formação dos comerciantes de Sakai; segundo, o de ter recebido influência do seu avô Sen'Ami, que servia ao shōgun Yoshimasa Ashikaga como "dōbōshü", isto é, encarregado de preparar "chakai" e outros entretenimentos. Mas, Rikyū começou a se dedicar com zelo ao estudo do "Chado", no ano de 1540, aos 19 anos. Nesse ano, ele se tornou discípulo de um "chajin" de renome, Takeno Jōō. Dizem que Rikyū, quando foi convidado por Jōō, pela primeira vez para um "chakai", pediu-lhe que aguardasse quatro dias, depois do que se apresentou vestido de monge budista, mudando inclusive o nome para Sōeki, nome eclesiástico, mostrando assim, ao mestre, a sua decisão de, daí para a frente, se dedicar ao "Chad $\bar{o}^{-1}$.

Durante os 30 anos seguintes, até 1570, ano em que ele passou a servir ao homem mais poderoso da época, Nobunaga Oda, Rikyū permaneceu apenas como "chajin", patrocinando "chakai", ensinando Chá, apreciando e colecionando valiosos utensílios usados na cerimônia do Chá e "kakemono" (pinturas ou caligrafias em papel ou seda, fixadas sobre um rolo de papel). Nessa época, Rikyū, além do título de Sōeki, usava o título de Hōsensai. Quanto ao nome Hōsensai, "ho" significa o ato de jogar algo, e "sen" significa um instrumento de bambu usado para pegar peixes. Isto se relaciona ao fato de Rikyū ter sido atacadista de peixe e a palavra "sen" tem a mesma pronúncia da palavra "chasen", que é o batedor de bambu, usado no preparo do Chá. A palavra "hōsen", cuja origem é atribuída às palavras de Zhuang-zi, um filósofo chinês do século IV A.C., é explicada por Rikyū da seguinte maneira: "assim como o instrumento para pegar peixes perde a sua importância uma vez utilizado, o elemento mais necessário para se alcançar um objetivo é abandonado logo que este for alcançado. Portanto, para se chegar ao verdadeiro caminho é necessária a determinação prévia de abandonar tudo, até aquilo que é considerado mais importante, para se atingir o " $m u$ ", isto é, o nada". É uma espécie de idéia paradoxal contida na filosofia Zen. 
Vamos, então, observar a história do desenvolvimento do "Cha$d \overline{\bar{o}^{\prime \prime}}$, e verificar qual era a sua forma antes de Rikyū.

No século VIII, na China, o chá se difundiu entre as classes altas como um tipo de remédio fortificante. No ano de 815, um monge budista chamado Eichū, ao retornar de um estágio na China, levou mudas de chá para o Japão e, assim, começou o seu cultivo nas aldeias ao redor de Quioto e perto do Lago Biwa. Este chá foi oferecido também ao imperador, fato que deu início à entrada do chá no Japão. Começaram a aparecer apreciadores de chá nos templos e no palácio imperial. Entretanto, no ano de 894, o governo japonês interrompeu o envio de missões oficiais à China. Conseqüentemente, a influência cultural chinesa no Japão diminuiu de repente, e o costume de tomar chá, que foi importado da China, também foi se extinguindo gradativamente.

Trezentos anos depois, porém, Eisai, o fundador da seita Rinzai do Budismo-Zen, após terminar seus estudos na China, regressou ao Japão no ano de 1191, trazendo novamente o chá. Foi então que o costume de tomar chá começou a se difundir nos templos Zen, como uma cerimônia espiritual de refeição em grupo, criando-se o "charei" (ritual de tomar chá silenciosa e solenemente) com a finalidade de acalmar o espírito.

Este "charei" tornou-se um dos mais importantes fatores da cultura Zen, difundindo-se também largamente entre os samurais, adeptos da seita Rinzai.

No século XIV, no entanto, o Chá, expandindo-se para fora dos templos, começou a se tornar uma prática suntuosa. A sala onde se realizava o "chakai" passou a ser ornamentada com adornos chineses luxuosos, muito caros na época, sendo que tanto os utensílios, quanto o próprio chá eram importados da China. Dessa maneira, o anfitrião se orgulhava cada vez mais da suntuosidade dos seus "chakai".

Em meados do século XIV, à medida que o chá se propagou largamente entre o povo como uma bebida muito apreciada, o "chakai" começou a ter sobretudo o caráter de entretenimento. Tornou-se popular o "chakai" chamado "Yonshu Juppuku" (quatro marcas e dez goles), onde os convidados tomavam o chá e adivinhavam as suas marcas. Vou exemplificar esta espécie de divertimento, tomando como exemplo o uísque. Em primeiro lugar, o anfitrião diz aos convidados três marcas de uísque: Johny Walker, Suntory e Old Eight; e pede-lhes para experimentá-los. Depois, acrescentando mais um de marca anônima, enche dez copos com os quatro uísques. Os convida- 
dos provam a bebida dos dez copos e procuram adivinhar a marca de cada um; são premiádos na proporção em que acertam. Percebemos que, além de entretenimento, tinha também as características de um jogo de azar. E provável que esse tipo de divertimento tenha se

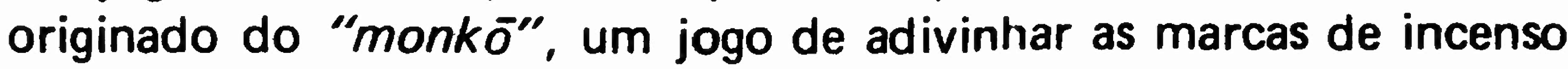
pelo odor de cada um, e que então estava em moda.

E notável, além disso, o fato de que já nessa época, o chá era cultivado largamente em várias regiões, observando-se a existência de várias marcas do produto. Mas o caráter de divertimento e de jogo foi se acentuando cada vez mais nos fins do século XIV. Havia, por exemplo, o "chakai" de "quatro marcas e dez goles" seguido por uma rodada de bebida, onde todos cantavam e dançavam junto com as damas de companhia, o que mostra que até o fator "sexo" fora introduzido no "chakai". Mas é importante notar que as regras para preparar e tomar o chá eram rigorosamente observadas, apesar da libertinagem que se verificava no "chakai".

Em meados do século XV, esse tipo de "chakai" entrou em declínio e começou a se desenvolver, entre o povo em geral, uma outra modalidade chamada "Rinkan no Cha", onde os convidados primeiro tomavam banho para se refrescar e, em seguida, saboreavam o chá e o saquê.

Mas esta maneira de tomar chá, isto é, divertir-se tomando chá, foi bastante modificada pelo shōgun Yoshimasa Ashikaga, famoso por ter construído o Ginkakuji (Pavilhão de Prata, de Quioto). Os "chakai" começaram a ser realizados em recintos fechados, como no "shoin" do Ginkakuji. "Shoin", literalmente, significa "sala de estudo". Mas, na prática, era uma sala simples, em estilo moderno da arquitetura da época, onde elementos novos, como "tokonoma"(2) e "chigaidana"(3), foram introduzidos. E importante notar que o Chá praticado até então, em que se usavam cadeiras como na China, passou a adotar o estilo japonês típico de se sentar, dobrando os joelhos sobre o "tatami"(4). Tal disciplina passou a ser fator obrigatório até mesmo nos treinamentos, quando se requisitava o uso de trajes de cerimônia.

Entretanto, ainda nessa época, os utensílios e "kakemono" chineses eram os preferidos. Por outro lado, os materiais didáticos e os livros clássicos chineses eram colocados no "chigaidana", fato que denotava, não só a ostentação como também, a erudição do anfitrião. Foi nessa época que o Chá começou a tomar características japonesas. 
Hoje, quando se fala em Rikyū, pensa-se imediatamente em 'Wabi Cha" (cerimônia praticada com humildade, desprendimento e simplicidade). Os primeiros passos do "Wabi Cha", porém, foram dados por Jukō Murata, "chajin" da segunda metade do século XV. Jukō foi o inventor da sala de chá de 4 "tatami" e meio, substituindo o "chakai" aristocrático realizado nas grandes salas do "shoin", por um mais simples e popular, num espaço menor, com os adornos da sala também simplificados. Diminuindo o espaço, ele pretendeu limitar o número de convidados a fim de se ter uma verdadeira comunhão espiritual entre todos. Jukō, mesmo utilizando utensílios chineses, deixou de lado os pomposos e requintados, preferindo os mais simples, que poderiam servir para uso diário. Foi Jukō quem promoveu a japonização do Chá, como podemos entender através de suas palavras: "a lua, sem nenhuma nuvem que a cubra, não é bonita". Ele encontrou a verdadeira beleza, não nas coisas perfeitas, mas nas que têm pequenas imperfeições.

Seu sucessor espiritual foi seu filho adotivo Sōju, e também Sōgo, mestre de Takeno Jōō, o já mencionado professor de Rikyū. Esta nova tendência do Chá penetrou na camada aristocrática. Sōju, que tinha amistosas relações com os monges Zen, foi o introdutor da filosofia do Zen no "Chado", criando "Cha-Zen Ichimi" lo espírito do "Chado" é igual ao do Zen, razão pela qual, a aprendizagem também é única).

Foi Jōō, mestre de Rikyū, quem desenvolveu ainda mais esse esp f- $^{-}$ rito de "Wabi Cha".

Jōō era grande comerciante de couro em Sakai. Sendo o couro a matéria-prima para a produção de armamentos e arreios, sua comercialização permitiu a Rikyū o contacto com os samurais. Jōō estudou a filosofia do Zen e era grande conhecedor dos escritores clássicos. Passou a estudar, com Sanetaka Sanjō Nishi, que era, na época, a autoridade máxima em crítica do poema japonês. Portanto, foi Jōō quem introduziu a estética tradicional da literatura japonesa no "Chado", tornando-o ainda mais japonês.

Assim, o "kakemono" para as salas de chá era restrito aos manuscritos dos monges Zen, mas Jōó colocou na sua sala de chá um poema (Waka), de Sadaie Fujiwara, cuja produção floresceu mais a partir dos fins do século XII até os fins do século XIII. Ele preferiu cerâmicas japonesas, como Shigaraki, Bizen (de cores finas); inventou o "futa-oki" (porta-tampa), o "jizaikagi" (gancho com suporte de bambu para pendurar chaleiras), o "mizusashi" de madeira (recipiente 
para água), o "kensui" de madeira (recipiente para água usada), aperfeiçoando o "Wabi Cha" popular, com seu colorido popular.

Rikyū veio a servir a Nobunaga Oda no ano de 1570, recomendado por Sókyū Imai, um "chajin" e fabricante de armas de fogo e de pólvora, da cidade de Sakai. Desde então, Rikyū deixou os seus negócios sob administração de terceiros e tornou-se um "cha-no-yu-sha", isto é, um profissional, mestre de "Chado", a serviço de um grande senhor, como Nobunaga. Rikyū organizava "chakai" para o seu senhor, praparava o Chá, avaliava os utensílios usados no Chá e acompanhava-o em suas viagens. Nobunaga confiava muito em Rikyū e, em 1575, nomeou-o "Sado", que significa chefe dos assuntos relacionados com o Chá. Em novembro do mesmo ano, Nobunaga realizou um "chakai" para comemorar a contenção da revolta dos adeptos da seita "Jōdo-shinshü" que ameaçava seu domínio político. Foram convidados "chajin" representativos de Quioto e Sakai, e foi Rikyū que preparou o Chá nessa ocasião, fato que marca a consolidação de sua elevada posição.

É fácil observar que o Chá dessa época estava fortemente vinculado à política e era comum realizar-se negociaçőes políticas ou diplomáticas e até conspirações, durante os "chakai". Quando terminava uma guerra, eram promovidos "chakai", ocasião em que os vencidos, além de serem obrigados a ofertar suas terras e seus bens, eram obrigados a entregar os utensílios de chá, considerados elementos valiosos e de extrema importância.

Portanto, "Sado" era um avaliador e intermediário na tomada desses utensílios; era o elemento que assistia a importantes encontros políticos a portas fechadas, razão pela qual, se tornou uma figura dos bastidores de extrema importância política.

Depois de Nobunaga ter sido assassinado em 1582, Rikyū aproximou-se do poderoso Hideyoshi Toyotomi, sucessor de Nobunaga. Homem de aguda intuição, Rikyū, já o havia presenteado com valiosos utensílios antes da morte de Nobunaga. Nobunaga, reconhecendo a importância do "Chado" na política, proibira a sua prática sem a sua autorização. Entretanto, Hideyoshi, tendo obtido essa autorização, preparava o Chá muito mais assiduamente que o próprio Nobunaga, construindo salas de chá, colecionando "kakemono" e outros utensílios, convidando pessoas e fazendo política de salas de chá.

Em 1582, quando construiu o castelo de Yamazaki, Hideyoshi ordenou a Rikyú que fizesse a planta da sala de chá. Este projetou-a com apenas 2 "tatami" e um "tokonoma", sem nenhum adorno. Esta 
sala de chá, cujo espaço abrangia menos da metade daquela idealizada por Jukō. contava com o espaço mínimo necessário para convidar pessoas.

No mesmo ano, foi construído, por Hideyoshi, o castelo de Ōsaka onde Rikyū projetou uma sala de chá ao qual deu o nome de "Vila da Montanha". Era também de 2 "tatami" e o que o caracterizava era o fato dela ter sido projetada como um recinto independente da casa principal, e que passou a ser denominada "sukiya". Para o jardim, escolheu plantas comuns das montanhas. Assim, a sala de chá ficou mais fechada e mais própria para o "Wabi Cha".

Mas, ao mesmo tempo, Hideyoshi projetou, no mesmo castelo de Ósaka, uma sala de 3 "tatami" chamada "Sala Dourada", cujo teto, paredes, colunas e esquadrias das portas eram folheadas a ouro. No "tatami", cujas bordas também eram confeccionadas com fios dourados, estenderam-se peles de orangotango. Todos os utensílios nessa sala, exceto o "chasen" e "chashaku", feitos de bambu, eram dourados. Isto contrastava totalmente com o espírito do "Wabi Cha" de Rikyū. Há, portanto, quem diga que Rikyū não tinha participado do projeto desta sala. Entretanto, tendo em conta que os comerciantes de Sakai adoravam o ouro, acredita-se que, na realidade, Rikyú tenha participado do referido projeto.

Em 1585, Hideyoshi dominou todo o Japão e decidiu realizar, pela primeira vez, um "chakai", no palácio imperial, para oferecer Chá ao imperador. Rikyū foi nomeado para preparar este "chakai", mas mesmo sendo "Sadō" de Hideyoshi, por ser de origem plebéia, não tinha o privilégio de entrar no palácio. Então, autorizado pelo imperador, foi-lhe outorgado o nome Rikyū, um título "Koii". "Ko${ } i^{\prime \prime}$ significa monge do Zen, que se aperfeiçoa sem se submeter ao isolamento, mas que desfruta dos mesmos privilégios dos que fazem esse retiro espiritual. Não se sabe, com exatidão, o significado do nome Rikyū, pois o documento que registrava a origem do título foi queimado por Hideyoshi quando Rikyū foi obrigado a se suicidar. Entre as várias interpretações, a mais divulgada diz que o nome significa "abandonei a honra e a riqueza"; mas a tese mais atual o interpreta como "uma broca velha e gasta", querendo dizer: "um velho caduco". De qualquer modo, através deste "chakai", no palácio imperial, Rikyū conseguiu o prestígio e autoridade máxima de um "chajin".

A influência de Rikyū não se restringe apenas ao Chá, mas estendeu-se também à política e à diplomacia, razão pela qual, as pessoas 
que pretendiam se aproximar de Hideyoshi, desde os comerciantes até os senhores feudais, procuravam obter a confiança de Rikyū, sendo que o próprio Hideyoshi consultava-o para resolver problemas politicos difíceis.

Na época, comentava-se: "Rikyū é a única pessoa capaz de falar de maneira franca com Hideyoshi" ou "a política é exercida aparentemente por Hideyoshi; entretanto, quem a exerce de fato é Rikyü".

Em 1587, por ordem de Hideyoshi, Rikyū realizou, no Santuário de Kitano, um famoso "chakai" a que foram convidados até comerciantes e camponeses. Ele organizava dezenas de "chakai" todos os meses e chegou até mesmo a acompanhar Hideyoshi na expedição de Odawara.

Agora, vamos ver a diferença entre o "Chado" de Rikyū e os que o precederam. Em primeiro lugar, ele desenvolveu o ideal estético e espiritual do mestre $J \bar{o} \bar{o}$, utilizando utensílios simples encontrados em qualquer casa, como vasos de bambu ou cestas para carvão, feitas de cabaça. As tigelas caras importadas da China, ele preferiu tigelas coreanas de uso cotidiano, e incentivou a criação de novas cerâmicas japonesas, como "Raku-yaki", de cor preta ou fria, todas de tamanho menor e de tato macio. Ele evitou ornamentar a sala com flores de cores vivas e perfumes fortes, preferindo as flores simples, próprias de cadà estação. Na preparação do Chá, não usou o "daisu" (estante de 4 pés, para os utensílios do Chá). Fez com que a refeição após o "chakai" fosse bem simples, com arroz, sopa e mais um prato. Criou até uma sala de chá de um "tatami" e meio, tendo, na entrada do "nijiri-guchi" (pequena porta de mais ou menos um metro quadrado, inspirada nas casas dos pescadores), um porta-espadas, procurando criar o espírito de igualdade entre os samurais e os demais, dentro da sala de chá. Também foram de sua invenção, colocar o "chōzu-bachi" (tina para lavar as mãos) no "roji" (caminho), os "tobiishi" (pedras colocadas no jardim para se caminhar sobre elas) e a cerca baixa, feita de plantas.

Assim, a forma original do "Wabi Cha" foi admiravelmente aperfeiçoada por Rikyū.

Em fevereiro de 1951, Rikyū foi expulso do palácio, por Hideyoshi, sendo condenado ao "harakiri", em 28 do mesmo mês. Nesse dia, caiu uma chuva de granizo, com fortes trovoadas. Na sua casa de Quioto, cercada por 3 mil soldados, em sua sala de chá, ele se sentou no "tokonoma" e, escutando o ruído da água a ferver na chaleira, cortou o ventre com um punhal. Mas a parede impediu a livre movimen- 
tação dos seus braços. Murmurou: "Este "okiai" não está bom" (uma expressão do "Chado" que significa que a disposição ou a harmonia das coisas está imperfeita), arrancou o punhal do ventre, pegou as entranhas expostas, colocando-as no "Jizai-no-kagi", cortou a barriga em cruz, com toda a calma. Depois, um de seus discipulos - um samurai - decepou-Ihe a cabeça.

Rikyū, um "chajin", deveria ser decapitado, dada a sua condição de comerciante, mas praticou com perfeição o "harakiri", uma honra reservada somente aos samurais.

Rikyū deixou um testamento e um poema curto, em estilo chinês. Este poema é interpretado de várias maneiras, mas o conteúdo deve ser mais ou menos o seguinte: "Tenho setenta anos; neste momento, com este punhal vou cortar tudo, até Buda e "Dharma", e me tornar um homem livre".

Sobre o porquê de sua expulsão surgiram várias versões dentre as quais podemos enumerar as seguintes:

1. Rikyū obtivera lucro excessivo com a avaliação e comércio de utensílios do Chá.

2. Colocar a sua própria estátua na entrada do templo que havia sido construído em memória dos seus pais, sobre o qual passariam também pessoas importantes.

3. Rejeitara em permitir que sua filha viúva se tornasse amante de Hideyoshi.

4. Protestara contra a invasão da Coréia, por Hideyoshi.

5. Pertencia ao Cristianismo, que estava proibido, e tomara parte na tentativa de envenenar Hideyoshi.

6. Hideyoshi, no fundo, tinha aversão ao "Wabi Cha" de Rikyū.

Mas a razão mais importante da condenação de Rikyū deve ter sido a necessidade de contê-lo, pois apesar de ser comerciante de origem, começava a adquirir poderes de um senhor feudal, com relação à idéia de Hideyoshi que tentava consolidar o sistema feudal de classes.

A cabeça decapitada de Rikyū foi amarrada à sua estátua, a qual foi tirada do templo e colocada junto a uma ponte para ser exposta ao público.

Apesar da trágica morte de Rikyū, é de se estranhar que não exista nenhum documento da época que mostre compaixåo por ele.

Hechikan, "chajin" e amigo de Rikyū, que nunca servira aos poderosos, comentou: "Rikyū era uma pessoa sincera e digna quando jovem, mas, agora, ele se tornou frívolo. Ele conhece a prosperidade 
do homem mas não a decadência humana. Pobre dele que sofre tanto na busca da honra e dá riqueza apesar de a vida humana ser tão curta." Percebe-se, por estas palavras, que Hechikan previa, exatamente, o destino de Rikyū.

Possivelmente, o que eu thes acabei de relatar terá ferido a imagem que todos tinham de Rikyū. Mas creio que, sem conhecer a época e a forma como Rikyū viveu, não podemos compreender a sua verdadeira grandeza.

Sen Rikyū foi uma das personalidades mais atraentes da história do Japão e, juntamente com Zeami, do teatro Noh, é uma das figuras mais brilhantes que representam o espírito japonês da Idade Média.

Acredito também que Rikyū será, no futuro, cada vez mais decantado e idolatrado.

\section{NOTAS:}

1. "harakiri": suicídio em que o indivíduo corta seu próprio ventre com um punhal, após o que, uma outra pessoa the decepa a cabeça com o intuito de Ihe abreviar a morte.

2. "tokonoma": alcova das salas japonesas, onde se costuma colocar objetos de adorno.

3. "chigaidana": estantes do "tokonoma".

4. "tatami": esteiras feitas de palhas de arroz, trançadas, que forram o piso dos aposentos de uma casa japonesa.

Traduzido por:

"Chadō Urasenke São Paulo Seinenbu"

(Departamento dos Jovens da Escola Urasenke de São Paulol 